\title{
Study on the Implementation of Green Supply Chain Management
}

\author{
in Textile Enterprises
}

\author{
Fengfei Zhou \\ Tianjin Polytechnic University \\ Tianjin 300160, China \\ Tel: 86-22-2452-8438Ｅ-mail: zhoufengfei@tjpu.edu.cn
}

\begin{abstract}
The green supply chain management is a sort of modern management mode which could comprehensively consider the environmental influence and resource utilization efficiency in the whole supply chain and how to implement the green supply chain management in special industrial operation at present has become into one of hotspot problems. This article mainly studied the core contents that textile and apparel enterprises implemented green supply chain management.
\end{abstract}

Keywords: Green supply chain, Textile and apparel enterprises, Implementation principles

\section{Introduction}

Textile and apparel products are traditional products to earn foreign exchange through export in China, and for a long term, China has been the biggest export trade country of textile and apparel in the world. But since entering into the 21 st century, Chinese textile and apparel industry begun to face increasingly serious commercial environments, for example, the world textile and apparel trade cancelled the quota limit, and the international trade walls accumulated, and the formation of global information network and global market and the acceleration of technical reform make consumers' demands develop to the directions such as diversification, individuation, functionality and environmental protection with high requirements, and Chinese resources are increasingly deficient, and the environment is gradually depredated. Under this domestic and foreign commercial environment, the future survival and development of Chinese textile and apparel industry face large challenge. Simple management mode of "purchase to export" or the production and management mode of "vertical integration" have made the Chinese textile and apparel industry lack in activity, innovational ability and insufficient international competition. Under this background, the idea of "horizontal integration" begins to rise, and as the representative of this idea, the supply chain management increasingly prevails, and the green supply chain management has gradually become into the new concept for the sustainable development of the enterprises. However, it is not the simple problem of concept to really implement the green supply chain management in enterprises, and there are large numbers of works to do. This article mainly studies the core approaches and principles that textile enterprises implement the green supply chain management.

\section{Core contents that textile enterprises implement green supply chain management}

\subsection{Establishing the strategic assets view of green textile supply chain}

Since the concept of green supply chain management was first put forward by US Michigan State University in 1996 (Handfield, 1996, P.1295-1297), domestic and foreign academe begun to study various aspects of the green supply chain management (Beaman, 1999, P.332-342, Joseph, 2003, P.397-409, Jiuh-Biing, 2005, P.287-313, Aref A, 2005, P.330-353, Samir K, 2007, P.53-80, Wu, 2003, P.86-88, Wu, 2004, P.1-3, Liu, 2006, P.27-30, Wang, 2003, P.11-16, 47). Some foreign famous multinational companies such as Ford Motor Company, Hewlett-packard Company, Valuable Clean Group and General Electric Company regarded the supply chain management as the strategic assets and corporate cultures acquiring corporate competitive advantage to filter into various parts, various departments and various employees. The supply chain has been utilized as the strategic weapon to rewrite the competitive law in the industry and impel competitors to have to develop themselves. But for Chinese textile and apparel enterprises, it is a challenge, and if Chinese textile and apparel enterprises want to change "made in China" to "created by China" and walk on the road of sustainable development, they should implement not only green production, but also the green supply chain "from cradle to recurrence", that is to say, the green supply chain should be regarded as the strategic asset of enterprises and 
the strategic supply chain management should be implemented.

First, the green supply chain strategy composed by five basic collocation factors including green operation strategy, green outsourcing strategy, green channel strategy, green client service strategy and green asset network should be established. Second, the green supply strategic culture should be established, and the green supply chain management should be integrated into enterprise culture. Finally, the green supply chain strategy which can be organically integrated with green product strategy and green market strategy should be developed. Therefore, the green supply chain strategy which can accord with the competitive strategy, client demand strategy, strength status of textile and apparel enterprise and fit in with the environment should be developed.

\subsection{Developing a flow system of green textile supply chain}

When Chinese textile and apparel enterprises confirm the strategic status of green supply chain, they should describe a blueprint about green supply chain to integrate the rules of the flow relationships among various operation units in the supply chain, ensure the harmony among various flows with the base establishments of the supply chain and achieve the aim of the green textile supply chain. As viewed from the management objective, this blueprint should not only acquire the corporate competitive advantage and economic efficiency through implementing green supply chain management, but also reduce the negative influences of management to the least extent and maximize the social efficiencies such as the utilization rates of resource and energy. As viewed from management objects, the blueprint should include five aspects. The first one is the material suppliers which are middling enterprises such as fiber manufacturer, resin manufacturer, dye manufacturer and accessories manufacturer. The second one is the manufacturers which produce the middle products or final products such as yarn manufacturer, textile manufacturer, printing and dyeing manufacturer, apparel manufacturer and composite material manufacturer. The third one includes operators, distributors and shopkeepers. The fourth one includes consumption units or consumers. And the final one includes reclaim disposal manufacturers which compose an integrated positive supply chain and reverse supply chain with other suppliers, manufacturers, operators, distributors and consumers (Jiuh-Biing, 2005, P.287-313, Aref A, 2005, P.330-353). In the green textile supply chain management, the management objects become into the strategic partners among enterprises through many basic flows such as green plan, green stock, green manufacturing, green distribution, green logistics, green consumption and green reclaim. At the same time, to ensure the order of various flows and maximize the performance of the whole green supply chain, many technical support, information support and mechanism support such as decision-making support system, information management system, green evaluation system and support guarantee system should be established. According to former research results (Jiuh-Biing, 2005, P.287-313, Wu, 2003, P.86-88, Wang, 2003, P.82-87), combining with the characters of textile apparel industry, we develop the green textile supply chain flow system which is seen Figure 1.

\subsection{Designing an organization of performance based on green textile supply chain}

The operation flow needs corresponding organization structure. As viewed from the strategic status and flow system of the green supply chain management, the organization design of Chinese textile and apparel enterprises also need to add a green smartness integration supply chain organization (seen in Figure 2). The organization should possess following characters (Shoshanah, 2006). First, it can support the whole competitive strategy of the enterprise. Second, it has the skills and the core ability to implement all supply chain flow among the interior of the enterprise with its strategic partners. Third, it has established the effective green performance evaluation system. Fourth, it should follow a series of feasible design principle including the principle that form obeys the function (the supply chain organization must really reflect the green supply chain flow) and the equal principle of flow and responsibility and ability (each flow should arrange corresponding function department or responsible personnel takes on corresponding function and possesses corresponding ability). At the same time, the organization should possess following characteristics (Xu, 2004, P.80-82). The first one is the whole cooperation, and in the process of cooperation and interaction, the decision-making, execution, cooperation, feedback, follow and emergency disposal should be developed. The second one is the smart reaction, and aiming at complex and changeable market and competitive development, the organization should quickly make reasonable reactions and harmonize enterprise to implement new resource distribution and strategic and tactic adjustment. The third one is the three-dimensional communication, and in different enterprises, various levels operation and decision-making layers, the organization can implement three-dimensional information transfer and communication. The fourth one is the process drive, and the organization should drive the team through harmonizing the environment and process.

\subsection{Establishing the strategic cooperation mode of green textile supply chain}

The supply chain of textile apparel is longer than other supply chains in other industries, and for the whole supply chain, the latter includes many suppliers. But in fact, more enterprises are gradually reducing the strategic range, and they more and more focus on few core abilities. So the effective cooperation among enterprises in the green textile supply chain becomes into the base to acquire the best performance of the green textile supply chain management, and it is the most important strategic activity for enterprises, that is to say, to establish the cooperation relationship is same 
important with technological innovation, and the enterprise which possess the ability of effective cooperation can acquire effective competitive advantage. However, few executive officers of green textile supply chain can give a clear and specific definition of cooperation, because the cooperation comes down to many aspects which include not only many cooperation types, but extensive mutual activities, and information sharing among operation units and the R\&D of long-term production and marketing items.

At present, according to the cooperation extent and profundity, the cooperation partnership can divided into four sorts such as trade type, cooperative type, harmony type and cooperation type. The cooperation partners of trade type devote their minds to enhance the simplicity of trade execution and few of them are absorbed in reducing the cost of supply chain management and enhancing the income of supply chain. This sort of cooperation relationship needs few advanced information system, and it is the most basic cooperation relationship at present. The cooperation of cooperative type possesses higher level of information sharing, and it generally implements information communication through special electric data exchange network and internet. The cooperation of harmony type possesses more complex basic establishment and flow of information sharing than the cooperation of cooperative type, and both cooperation relationships are closer and they more depend on their ability each other. This sort of cooperation relationship needs the negotiation and compromise with higher level, and they all expect to benefit from long-term cooperation, and this cooperation is fitter for the key supply chain partners with strategic meaning. The cooperation of cooperation type can mutually invest in R\&D project and the development project of intellectual property rights, and the sharing degree covers from entity assets to knowledge assets even to the human resource. This sort of cooperation generally is called as "strategic alliance" which can not only share information but also develop information.

Though the strategic cooperation modes of the green textile supply chain are different, but the textile enterprise should establish "key" and "strategic" clients and suppliers accruing the rule that " $20 \%$ of clients will bring $80 \%$ of profits for the enterprise". The concrete method is to establish a selectable evaluation standard to evaluate and select the cooperation relationships and cooperation partners according to many special demands such as green strategy, culture, organization and technology. At the same time, textile enterprises also should follow following instructive principles to ensure the success of cooperation relationship. First, simplify the interior cooperation before cooperation. Second, customize the cooperation mode according to the importance degrees of cooperation partners. Third, ensure to sharing knowledge and information and assume mutual risks and benefits among cooperation partners. Fourth, trust each other. Fifth, confirm every cooperation partner's anticipation. Sixth, utilize the technology to support the cooperation relationship.

\subsection{Establishing a performance evaluation and management system of green textile supply chain}

For the textile enterprise which first introduces the green supply chain management, the establishment of the green textile supply chain performance evaluation and management system is the effective tool, and the effective supply chain performance evaluation system can tell enterprise whether various parts in the positive supply chain and reverse supply chain are really exerting function, and help enterprise to diagnose problems and continually correct problems. First, we should add green indexes into the general supply chain evaluation index system to establish effective green textile supply chain evaluation index system which can exactly reflect the green health status of the textile enterprise supply chain. Second, we should utilize the green textile supply chain evaluation index to support the strategic aim for textile enterprises and implement effective green textile supply chain performance management. Effective supply chain performance evaluation system must include following three sustainable activities (Anne-Marie, 2006, p.1427-1432), (1) making quantitative aims to accord with plan and budget, (2) establishing individual objective and department objective to accord with the total objective of textile enterprise, (3) establishing clear follow evaluation process and the mechanism and program of management performance.

At present, there are many articles to study the supply chain performance evaluation index system, and the structure research of the performance measurement system mainly includes two tendencies, and the first one is to establish a new system based on the advice model, and the second one is to adopt the performance measurement system with multiple advices. The performance evaluation and management system of the textile supply chain should possess following characters (Anne-Marie, 2006, p.1427-1432). First, the system has been implemented in other industries, and it is not only the concept theory. Second, the system is designed based on the environment of the supply chain. Third, the management system should be composed by the performance measurement which can be easily operated. The supply chain operation reference model (SCOR) is the first supply chain reference model based on performance measurement, and it has been in the growth stage of lifecycle and become into the standard in the industry. It is the most popular supply chain reference model which is adopted and accepted in the world. Therefore, in the performance evaluation system of SCOR, we can add green indexes about textile enterprises to establish the green textile supply chain performance evaluation and management system.

\section{Conclusions}

It has important meaning to implement green textile supply chain management for the sustainable development of 
Chinese textile enterprises and the whole industry, and it offers an ideal management mode for the harmony development of economic benefits and social benefits in Chinese textile enterprises. But at the same time, to really implement green supply chain management, there are works to do, we should not only establish the strategic assets view of green textile supply chain, but establish organization, cooperation mode and performance management system in the process of implementation.

\section{References}

Anne-Marie \& Jolly-Desodt. (2006). Benchmarking of the textile garment supply Chain using the SCOR model. 2006 international conference on service systems and service management. Troyes of France. V3. P.1427-1432.

Aref A. Hervani and Marilyn M. Helms. (2005). Performance measurement for green supply chain management. Benchmarking: An International Journal. No.12(4). P.330-353.

Beaman, B. M. (1999). Designing the green supply chain. Logistic Information Management. No.12(4). P.332-342.

Handfield R B. (1996). Green Supply Chain: Best Practices From the Furniture Industry. Proceedings Annual Meeting of the Decision Science Institute. USA. No.3. P.1295-1297.

Jiuh-Biing, Sheu, Yi-Hwa, Chou \& Chun-Chia Hu. (2005). An integrated logistics operational model for green-supply chain management. Transportation. Research Part E41. P.287-313.

Joseph Sarkis. (2003). A strategic decision framework for green supply chain management. Journal of Cleaner Production. No.11(4). P.397-409.

Liu, Qijun. (2006). Study on Supply Chain of Green Textile. Journal of Zhejiang Provincial Party School. No.6. P.27-30.

Samir K. Srivastava. (2007). Green supply-chain management: A state-of-the-art literature review. International Journal of Management Reviews. No.9(1). P.53-80.

Shoshanah Cohen \& Joseph Roussel, interpreted by Wangrong et al. (2006). Strategic Supply Chain Management. Beijing: People's Post and Telecommunication Publishing House.

Wang, Nengmin, Yangtong \& Qiao, Jianming. (2003). Study on Green Supply Chain Management. Industrial Engineering Journal. No.10(1). P.11-16, 47.

Wang, Yingluo, Wang, Nengmin \& Sun, Linyan. (2003). The Basic Principles of Green Supply Chain Management. Engineering Science. No.5(11). P.82-87.

Wu, Dichong \& Gu, Xinjian. (2003). Study of Green Textile Supply Chain and Its Organization. Journal of Textile Research. No.24(1). P.86-88.

Wu, Dichong. (2004). Study on Supply Chain of Green Textile. Silk Monthly. No.12. P.1-3.

Xu, Yimin. (2004). The Design of Order-oriented Agile Supply Chain Organization. Logistics Sci-Tech. No.8. P.80-82.

Yang, Hongjuan \& Tian, Cungang. (2004). The Sustainable Development Mode of Yunnan Enterprises: Green Supply Chain Management. Inquiry into Economic Problems. No.11. P.73-75. 


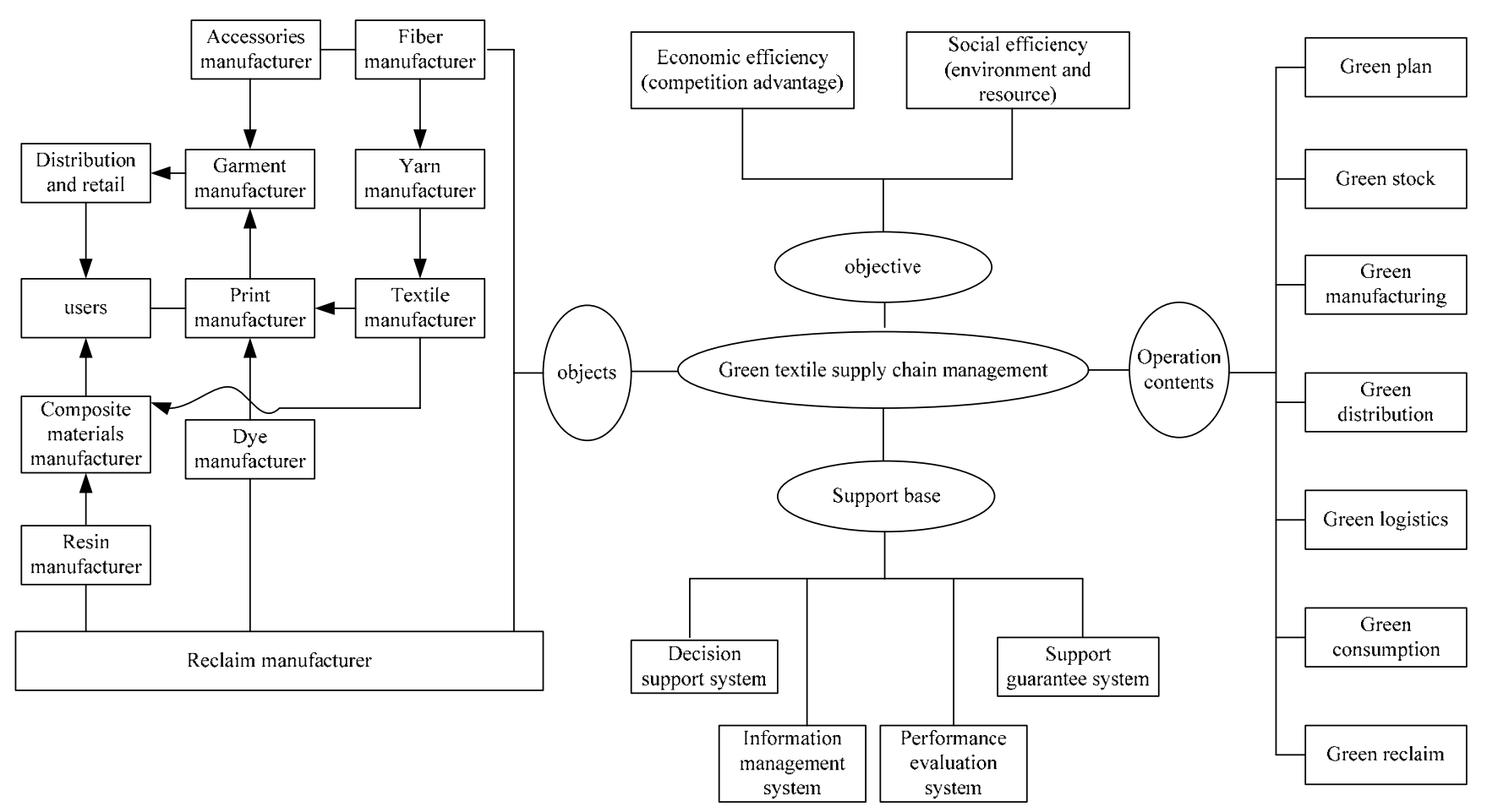

Figure 1. System of Green Textile Supply Chain Flow

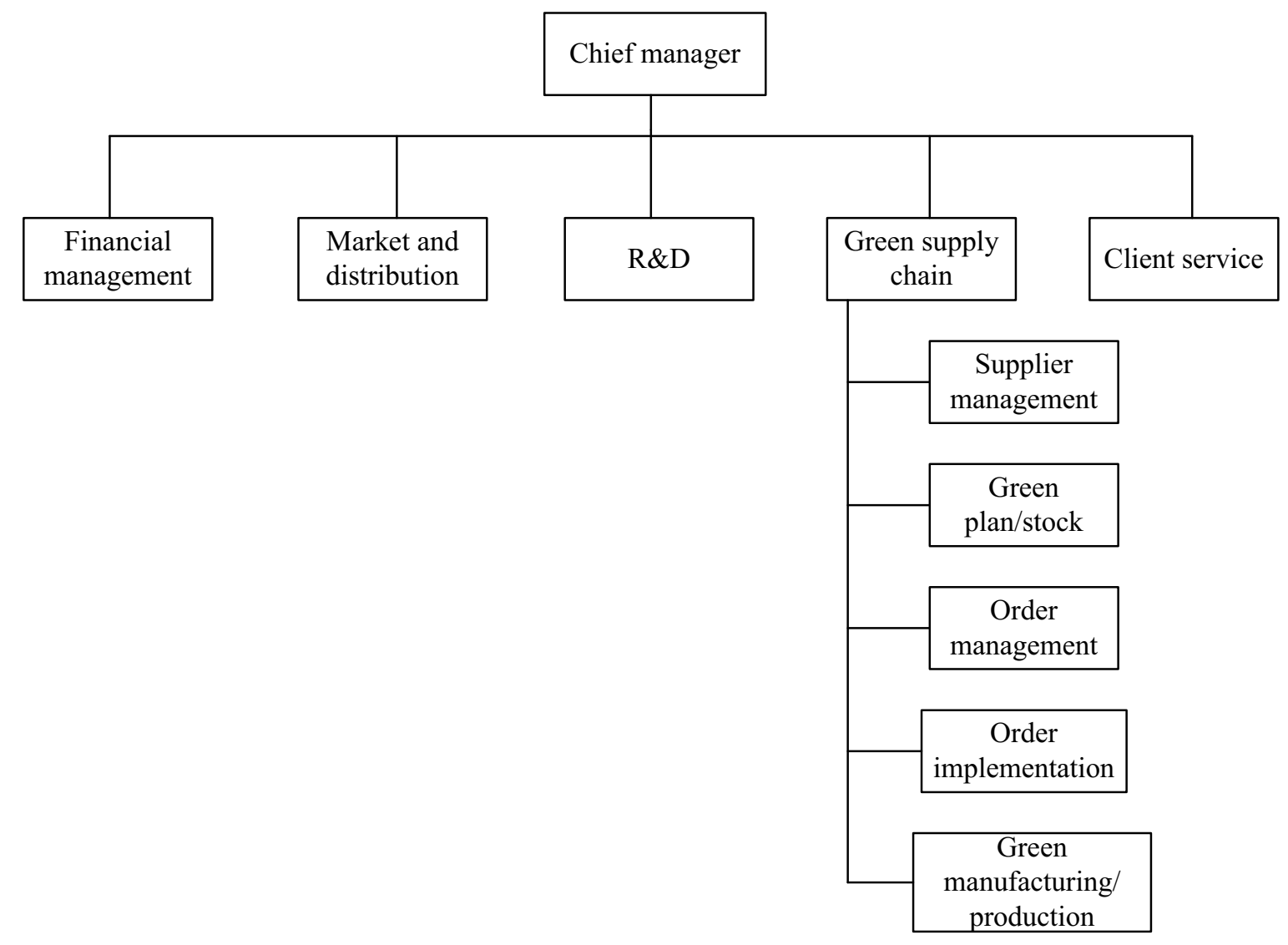

Figure 2. Organization of Green Smartness Integration Supply Chain 